\title{
Finite Element Analysis for Stiffened Steel Lined Reinforced Concrete Penstock
}

\author{
Ji Dongyu \\ Hunan Urban Construction College \\ Xiangtan, China \\ hnjdy@126.com
}

\author{
Xu Guanchao \\ North China University of Water Resources and \\ Electric Power \\ Zhengzhou, China \\ 285893543@qq.com
}

\begin{abstract}
Stiffening rings has a greater impact on the equivalent stress of steel, especially when the stiffening ring has proper spacing and the large rigidity, the stiffening ring will share part of the load, so it can lead to the circumferential stress of steel reduce. Selecting the appropriate stiffening ring spacing and sizes, you can improve the stress state of steel, so that the total amount of steel pipe is relatively more saving. In this paper, using the finite element method to do the finite element simulation analysis for the stiffened steel lined reinforced concrete penstock of Shuikou Hydropower Station, researched the distribution characteristics of stress and deformation, stress stiffening ring and the surrounding concrete, the deformation distribution and the influence of stiffening ring to the steel liner, outsourcing concrete stress distribution. The results show that Shuikou Hydropower Station using the structure of stiffened steel lined reinforced concrete penstock is economic rationality, the structure is safe and reliable, and it is able to meet the design requirements. The research can provide a reference to the design and construction of stiffened steel lined reinforced concrete penstock.
\end{abstract}

Keywords-Stiffened ring; Steel lined reinforced concrete; Penstock; Finite element method; Stress analysis.

\section{Project Overview}

The Shuikou Hydropower Station is located in the middle and lower reaches of Minjiang in Fujian Provimce, its installed capacity is $1400 \mathrm{MW}$, and the main hydraulic structures have concrete gravity dam, power house at dam toe, locks, etc. The gravity dam's height is $101 \mathrm{~m}$, the tatal length is $786 \mathrm{~m}$, and it isdivided into 42 dams[1]. Among them in wide $20.5 \mathrm{~m}$ diversion section buried the diameter $10.5 \mathrm{~m}$ steel penstock, the length of the steel penstock is $59.47 \mathrm{~m}[2]$. The hydropower station uses stiffened steel lined reinforced concrete penstock, penstock wall thickness $25 \mathrm{~mm}$, the stiffening ring thickness $28 \mathrm{~mm}$, height $230 \mathrm{~mm}$, spacing $1 \mathrm{~m}$. Penstock and stiffening ring with $16 \mathrm{MnR}$, elastic modulus Es $=210 \mathrm{GPa}$, yield strength 330MPa [3], the Poisson's ratio $\mu=0.3$. The water pressure is $0.7 \mathrm{MPa}$ in the penstock.

\section{Computational MODEL}

\section{A. Model Parameters.}

The nonlinear calculation of steel liner uses Mises yield criterion, secant modulus $21 \mathrm{GPa}$, poisson's ratio 0.3 . The concrete's nonlinear calculation open shear transfer coefficient is 0.35 , the tensile strength under hydrostatic pressure is $1.27 \mathrm{MPa}$, softening coefficient is 0.429 [4]. Steel liner nonlinear stress - strain curve is shown in Fig.1.

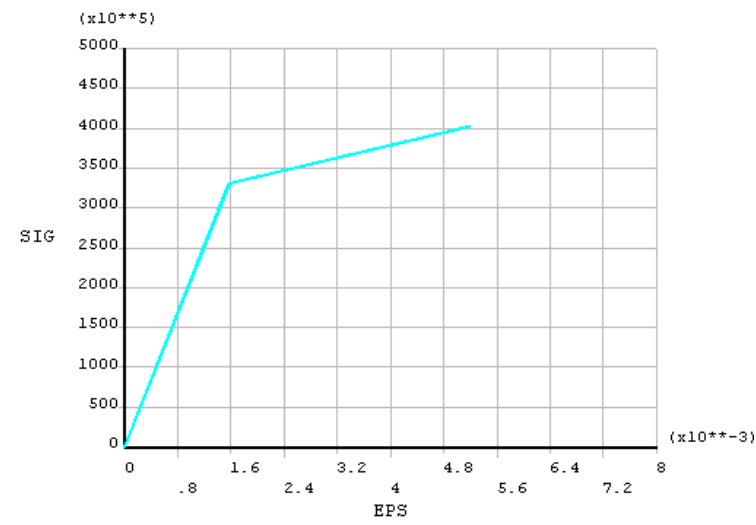

Figure 1. Steel liner stress - strain curve

B. The Element of Model.

Concrete pipe model uses 8-node isoparametric block element. It is used for the 3-D modeling of solid structures. The element is defined by eight nodes having three degrees of freedom at each node. The element has plasticity, creep, swelling, stress stiffening, large deflection, and large strain capabilities[5]. The steel model uses 4-node shell element. The element is defined by four nodes having six degrees of freedom at each node, including three translational degrees of freedom and three rotational degrees of freedom[6]. The finite element model of stiffened steel lined reinforced concrete penstock is shown in Fig. 2.

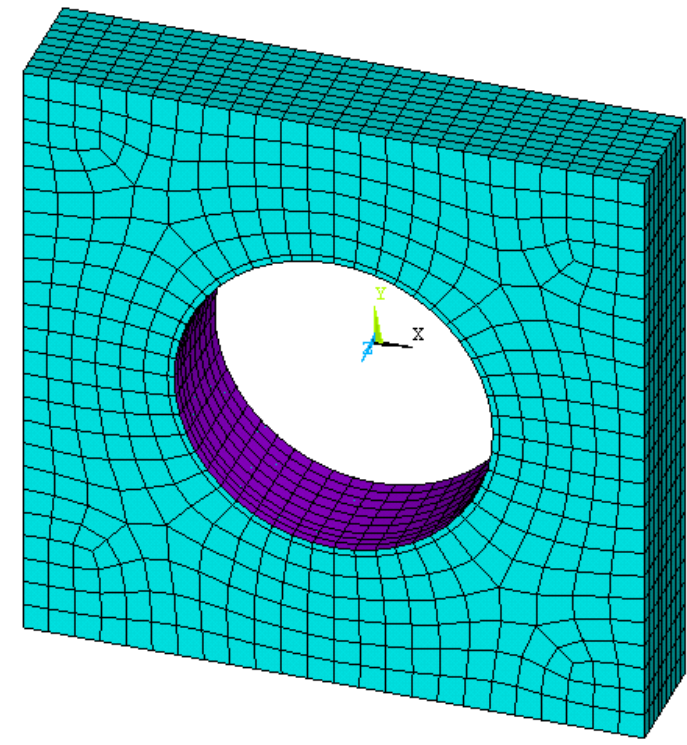

Figure 2. The finite element model of penstock 


\section{Calculation Case.}

Taking into account the running process of steel-lined reinforced concrete penstock mechanical characteristics [7], the mainly considered cases are the following two kinds: Case 1: The internal water pressure $(0.7 \mathrm{MPa})$, case 2: internal water pressure (1.4 MPa).

\section{Structural Analysis Pipeline}

\section{A Stress Analysis.}

Through the nonlinear finite element analysis of Shuikou Hydropower Station on stiffened steel lined reinforced concrete penstock, we get the circumferential stress cloud of outsourcing concrete pipe, steel and stiffening ring in various cases, as shown in Fig.3 to Fig.8.

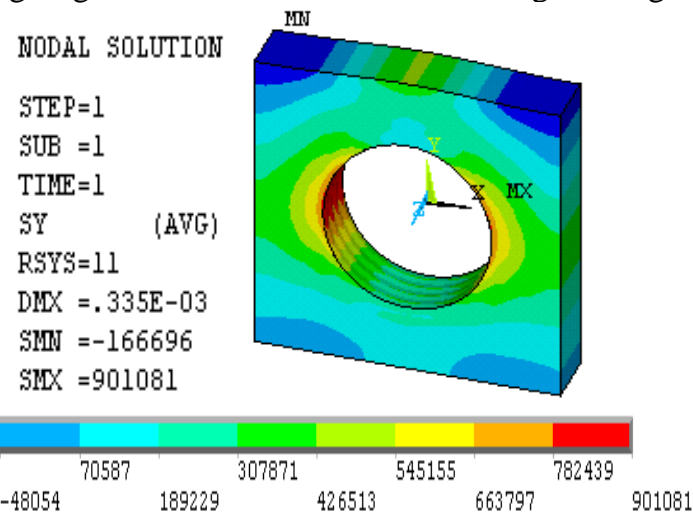

Figure 3. Circumferential stress cloud map of concrete pipe under case $1(\mathrm{~Pa})$

NODAL SOLUTION
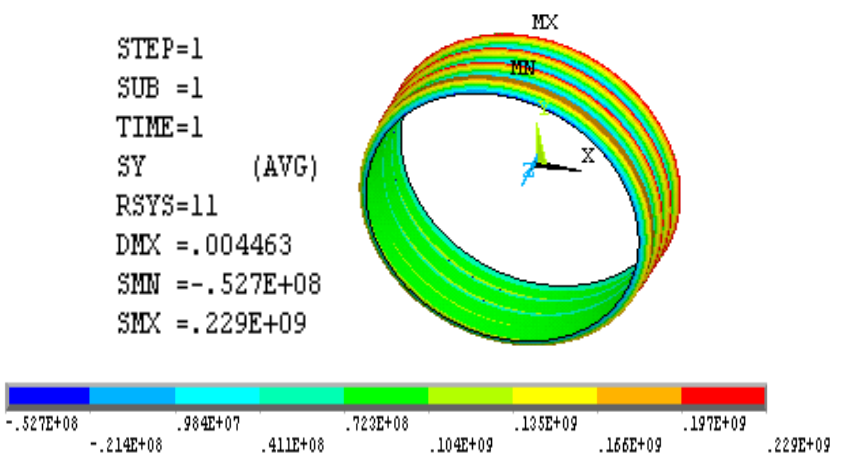

Figure 4. Circumferential stress cloud map of steel pipe under case $1(\mathrm{~Pa})$

\section{NODAL SOLUTION}
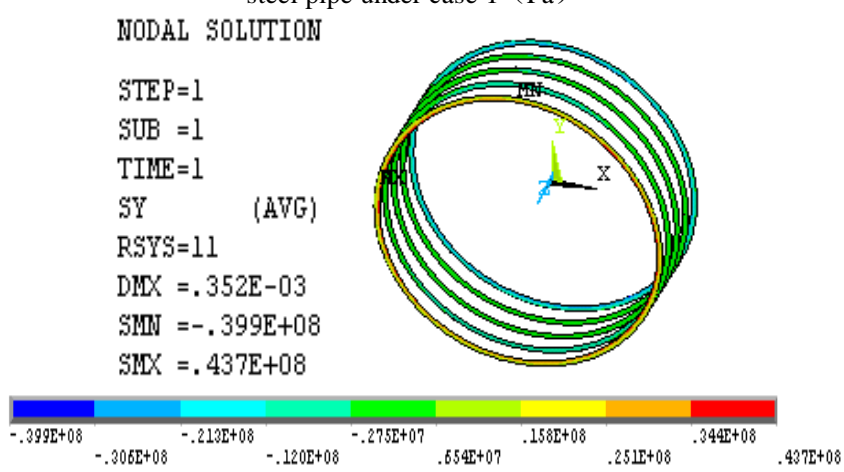

Figure 5. Circumferential stress cloud map of stiffened ring under case $1(\mathrm{~Pa})$

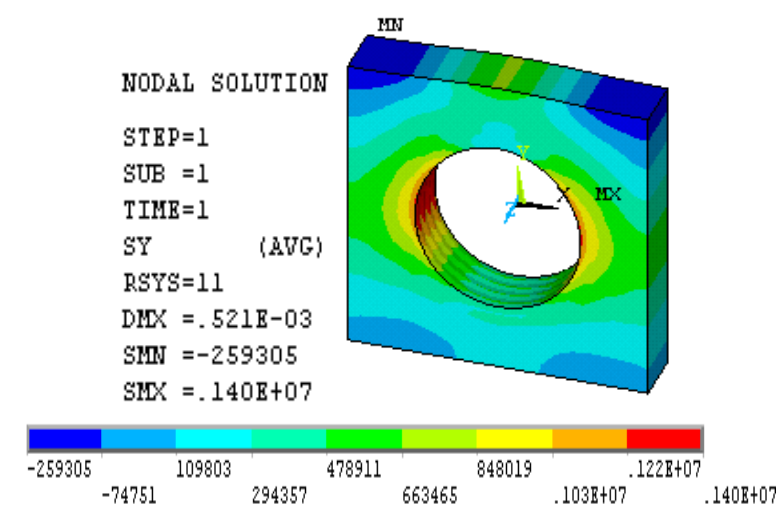

Figure 6. Circumferential stress cloud map of concrete pipe under case $2(\mathrm{~Pa})$

NODAL SOLUTION
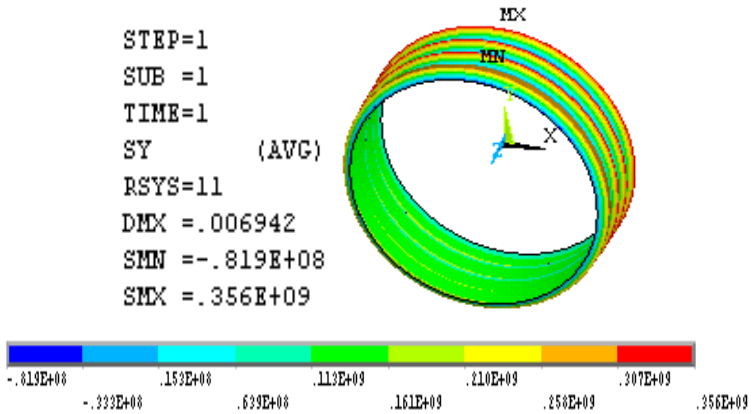

Figure 7. Circumferential stress cloud map of steel pipe under case $2(\mathrm{~Pa})$

NODAL SOLUTION

STEP $=1$

SUB $=1$

TIME $=1$

SY

RSYS $=11$

$\mathrm{DNX}=.548 \mathrm{~B}-03$

SMN $=-.621 \mathrm{E}+08$

$\operatorname{SMX}=.680 \mathrm{E}+08$
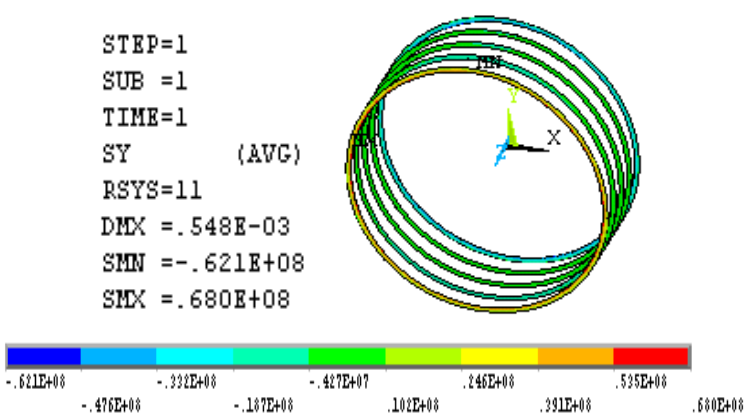

Figure 8. Circumferential stress cloud map of stiffened ring under case $2(\mathrm{~Pa})$

As can be seen from Fig.3 to Fig.8, in case 1, the largest circumferential stress of concrete pipe is $0.9 \mathrm{MPa}$, steel's maximum circumferential stress $229 \mathrm{MPa}$, the average circumferential stress $72.3 \mathrm{MPa}$, stiffening ring maximum circumferential stress $43.7 \mathrm{MPa}$,the average circumferential stress $-2.75 \mathrm{MPa}$. In case 2, the largest circumferential stress of concrete pipe is $1.4 \mathrm{MPa}$, the largest circumferential stress of steel $356 \mathrm{MPa}$, the average circumferential stress $113 \mathrm{MPa}$, the maximum circumferential stress of stiffening ring $68 \mathrm{MPa}$, the average circumferential stress $-4.27 \mathrm{MPa}$. Stiffening ring is mainly responsible for the compressive stress in the radial direction, in the outer of the ring 1 and 5 subject to tensile, the ring 2,3 and 4 subject to pressure, steel liner is mainly responsible for the hoop tensile stress. In case 2, the tensile strength of the concrete reach to the limit, partially cleaved[8]. 


\section{$B$ Deformation Analysis.}

When we do the deformation computation for the stiffened steel lined reinforced concrete penstock of Shuikou Hydropower Station, the positive $\mathrm{Y}$ axis is selected as the starting point on concrete pipes, the nodes at each $45^{\circ}$ clockwise rotation is the key points for the calculation, study the radial deformation distribution of the critical points' calculation. The radial displacement cloud of concrete pipe, steel pipe and stiffened ring, the radial displacement curve of key points are shown in Fig.9 to Fig.16.

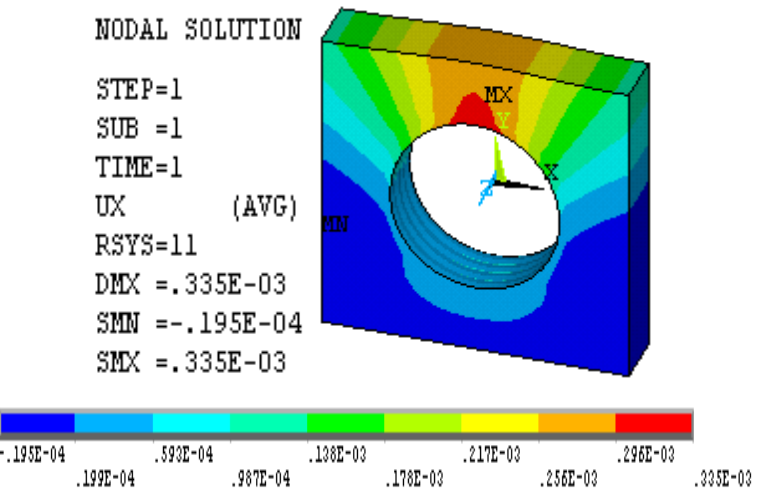

Figure 9. Radial displacement cloud map of concrete pipe under case $1(\mathrm{~m})$
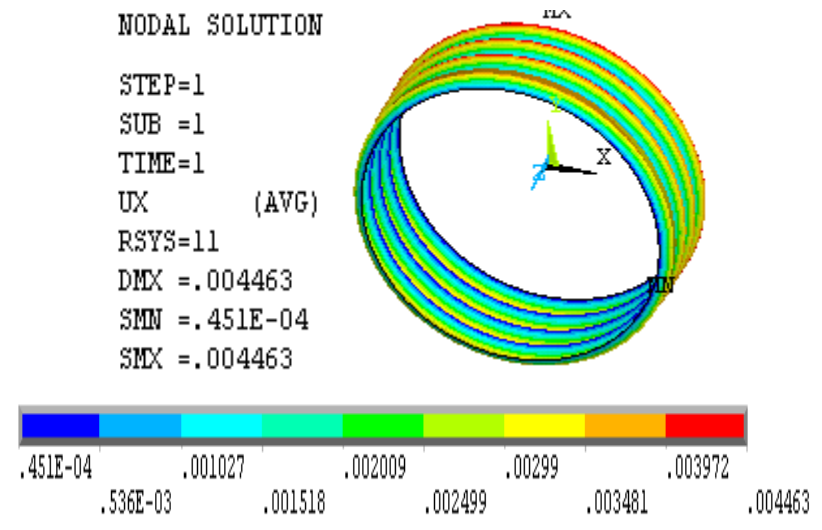

Figure 10. Radial displacement cloud map of steel pipe under case 1 (m)
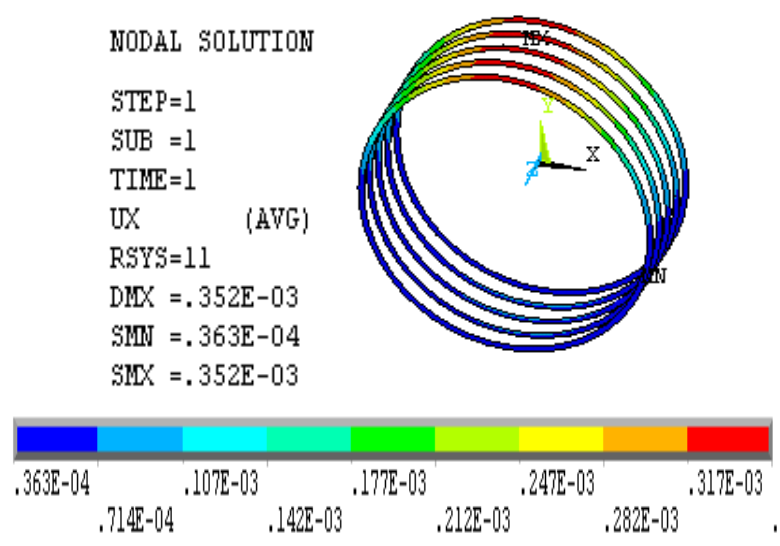

Figure 11. Radial displacement cloud map of stiffened ring under case 1 (m)

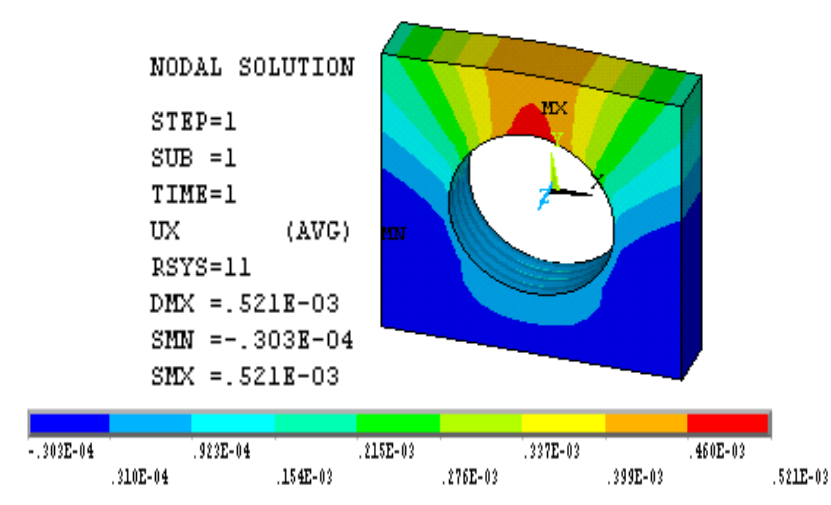

Figure 12. Radial displacement cloud map of concrete pipe under case $2(\mathrm{~m})$

\section{NODAL SOLUTION}
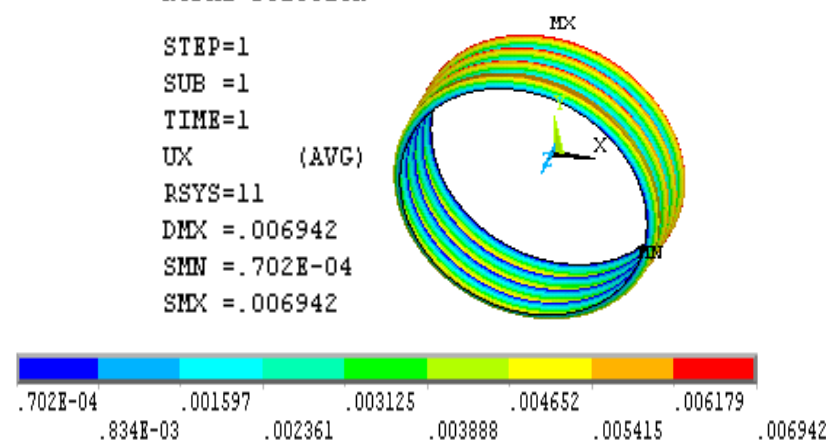

Figure 13. Radial displacement cloud map of steel pipe under case $2(\mathrm{~m})$

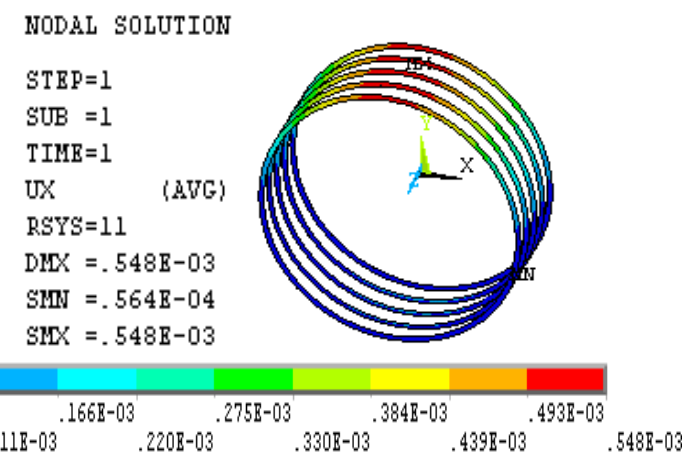

Figure 14. Radial displacement cloud map of stiffened ring under case $2(\mathrm{~m})$

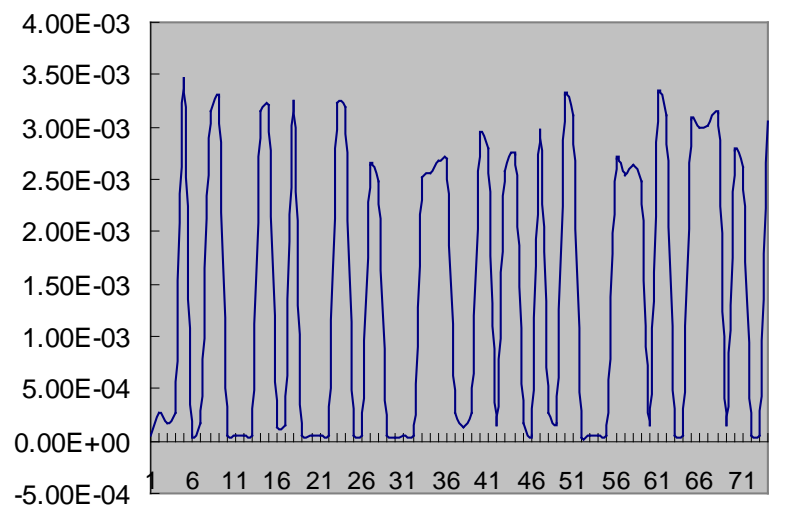

Figure 15. Radial displacement curve of key points under case 1 (m) 


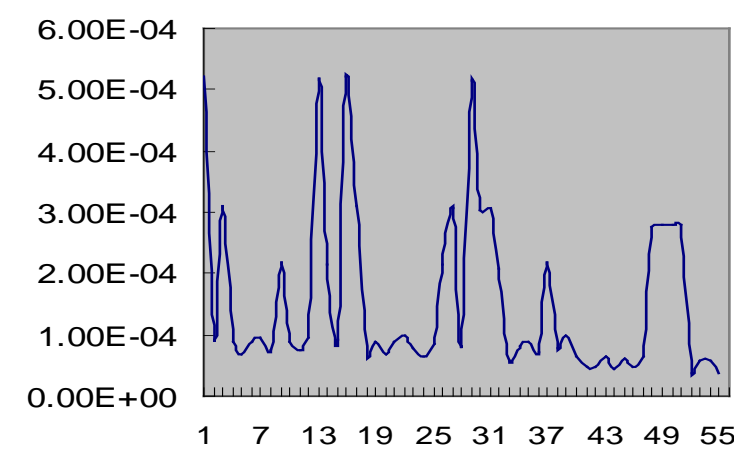

Figure 16. Radial displacement curve of key points under case 2（m)

As we can see from Fig.9 to Fig.16, the radial displacement of the stiffened steel lined reinforced concrete penstock is small in each case, in case 1 the maximum radial displacement $0.34 \mathrm{~mm}$, in case 2 the maximum radial displacement. $052 \mathrm{~mm}$. As we can see from Fig.15, in same position we take 9 nodes along the negative $\mathrm{z}$ axis, namely $0-9$ represent $0^{\circ}$ direction, 10-18 represent $45^{\circ}$ direction. From the line chart we know that the displacement of steel lined with stiffening ring is smaller than without stiffening ring, and it will appear a larger displacement region between two stiffening rings. This is due to the junction of the stiffening ring and the steel pipe the stress suddenly increases[9]. As can be seen from Fig.16, in the same position along the negative $\mathrm{z}$-axis takes seven nodes, namely 1-7 represent $0^{\circ}$ directions, 814 represents $45^{\circ}$ directions. By line chart shows that the radial displacement appears a larger value along the $0^{\circ}$ direction, which is due to the concrete on the top of the dam is thinner, so the section is dangerous, but the displacement with stiffening ring is smaller in the position[10].

\section{CONCLUSION}

In summary, the Shuikou Hydropower Station using the structural form of stiffened steel lined reinforced concrete penstock is economically reasonable, the penstock force structure clear, through reinforcement strengthened t, so it can meet the strength requirements. Radial displacement of the penstock is small, so it can meet the stiffness requirements.

\section{REFERENCE}

[1] Wei Zhang, Hegao Wu. Study on safety performance of bearing capacity of penstock on downstream face of dam [J]. Water resources and hydropower engineering, 2008,39(9):40-43.

[2] Suohong Jiang. Application of the elasticity center method of structure mechanics for penstock laid on the downstream face of dam [J]. Water power, 2003,29(9):31-34.

[3] SL191-2008. Design Code for Hydraulic Concrete Structure[S]. China Water Conservancy and Hydropower Press, 2008.

[4] Jianjing Jiang, Xinzheng Lu, Lieping Ye. Finite Element Analysis of Concrete Structures [M]. Tsinghua University Press, 2004.

[5] Bofang Zhu. Finite Element Method Principle and Application [M]. China Water Conservancy and Hydropower Press, 1998.

[6] Xucheng Wang. Finite Element Method [M]. Tsinghua University Press, 2003.

[7] Shanding Ma, Ruze Wang. Hydropower Station Structures (The Second Edition) [M]. China Water Conservancy and Hydropower Press, 1996.

[8] Congbao Wang, Hegao Wu. Comparison Analysis of Elasticity Center Method and Finite Element Method for Penstock Laid on Downstream Surface of Dam [J]. Water resources and power, 2005,23(4):8-11.

[9] Wei Zhang, Hegao Wu. Safety evaluation of the joint between stee lined reinforced concrete penstock laid on downstream face of dam [J]. Rock and soil mechanics, 2010,31(3):799-804.

[10] Hegao Wu, Wei Zhang. Study on wall thickness of steel lined reinforced concrete penstock laid on downstream surface of dam [J]. Journal of hydraulic engineering, 2006, 37(9):1085-1091. 